\title{
PERBANDINGAN METODE FUZZY INFERENSI TSUKAMOTO DAN SUGENO UNTUK MEMPREDIKSI PEMESANAN ROTI JORDAN
}

\author{
Ferly Ardhy1), Dwi marisa Efendi' ${ }^{2)}$ \\ ${ }^{1)}$ Sistem Informasi, STMIK Dian Cipta Cendikia Kotabumi \\ ${ }^{2)}$ Teknik Komputer, STMIK Dian Cipta Cendikia Kotabumi \\ Jl. Negara No.03 candimas Kotabumi Lampung Utara \\ Email:ferly@dcc.ac.id ${ }^{1)}$,dwimarisa89@gmail.com ${ }^{2)}$,
}

\begin{abstract}
PD Nur berkah jaya merupakan usaha dagang yang menjual berbagai macam jenis makanan terutama roti dengan nama roti jordan. PD Nur Berkah jaya sangat membutuhkan peramalan untuk menentukan jumlah permintaan dan pembelian barang untuk meningkatkan jumlah keuntungan dan menghindari terjadinya kelebihan dan kekurangan persediaan di gudang. Peramalan atau prediksi yang digunakan adalah dengan membandingkan dua metode yaitu metode Tsukamoto dan Sugeno dengan menggunakan sembilan rule untuk mentukan metode yang mana yang memiliki nilai MSE terendah. Berdasarkan perbandingan metode yang digunakan diketahui bahwa metode sugeno memiliki nilai MSE terendah dengan nilai mencapai $0,0176 \%$
\end{abstract}

Kata Kunci : Metode Tsukamoto, Metode Sugeno, MSE

\section{Pendahuluan}

Perusahaan Dagang (PD) Nur Berkah Jaya Way Kanan merupakan suatu perusahaan yang bergerak dalam bidang Permintaan, Perusahaan tersebut menjual berbagai macam makanan ringan seperti coklat, roti, wafer, makanan ringan dan banyak jenis lainnya. Salah satu produk yang sangat tinggi daya jualnya pada PD Nur Berkah Jaya adalah Produk roti, berbagai macam produk roti yang dijual salah satu produk yang paling diminati adalah roti bermerk Jordan sehingga menuntut perusahaan untuk menyediakan stock roti lebih banyak dari produk snack roti lainnya.

Penelitian dengan menggunakan logika fuzzy yang sebelumnya pernah dilakukan adalah dengan judul "Penerapan metode Tsukamoto (Logika Fuzzy) dalam sistem pendukung keputusan untuk menentukan jumlah produksi roti jordan berdasarkan data persediaan dan jumlah permintaan". Penelitian tersebut dilakukan oleh Ginanjar Abdurahman, dalam penelitian tersebut disimpulkan bahwa hasil perhitungan sistem yang dilakukan tidak berbeda dengan hasil perhitungan secara manual, hal ini dibuktikan dengan uji validitas dua puluh data sampel. sistem ini dapat berjalan lebih singkat tanpa mengurangi ketepatan dalam perhitungan (Minarni and Aldyanto, F. 2016).

\section{Pembahasan}

\section{1 himpunan Fuzzy}

Himpunan fuzzy dari semesta U dikelompokkan oleh fungsi keanggotaan $\mu_{\mathrm{A}}(\mathrm{x})$ yang berada pada nilai antara $[0,1]$. Fungsi keanggotaan dari himpunan klasik hanya memiliki dua nilai yaitu 0 dan 1 , sedangkan fungsi keanggotaan himpunan fuzzy merupakan fungsi kontinyu dengan range $[0,1]$.

\subsection{Fuzzy Tsukamoto}

Dalam inferensinya fuzzy Tsukamoto melalui beberapa tahapan sebagai berikut menurut (Ayuningtias, L.P., dkk. 2017) :

1. Fuzzyfikasi yaitu proses untuk mengubah input sistem yang mempunyai nilai tegas menjadi variabel linguistik menggunakan fungsi keanggotaan yang disimpan dalam basis pengetahuan fuzzy.

2. Pembentukan basis pengetahuan fuzzy ( rule dalam bentuk IF THEN), yaitu secara umum bentuk model fuzzy Tsukamoto adalah IF ( $\mathrm{X}$ IS A) and (Y IS B) and (Z IS C), dimana A,B, dan $C$ adala himpunan fuzzy.

3. Mesin inferensi yaitu proses dengan menggunakan fungsi implikasi MIN untuk mendapatkan nilai $\alpha$-predikat tiap tiap rule $(\alpha 1$, $\alpha 2, \alpha 3, \ldots . \alpha$ n). Kemudian masing masing nilai $\alpha$-predikat ini digunakan untuk menghitung keluaran hasil inferensi secara tegas (crisp) masing masing rule (z1, z2, z3,....zn).

4. Defuzzyfikasi dengan menggunakan metode rata rata (average): 


\subsection{Fuzzy Sugeno}

$$
\mathrm{Z}=\frac{\sum a 1 . \mathrm{Z} 1}{\sum a 1}
$$

Metode Sugeno diperkenalkan oleh Takagi Sugeno Kang pada tahun 1985 (Ayuningtias, L.P., dkk. 2017).

\subsection{Fuzzy Sugeno}

Secara umum bentuk fuzzy Sugeno adalah

If ( $\mathrm{X} 1$ is $\mathrm{A} 1) \mathrm{O}(\mathrm{X} 2$ is $\mathrm{A} 2) \mathrm{O}(\mathrm{X} 3$ is $\mathrm{A} 3) \mathrm{O} \ldots . \mathrm{O}(\mathrm{Xn}$ is An) THEN $z=k$ dengan Ai adalah himpunan fuzzy ke-i sebagai anteseden, dan $\mathrm{k}$ adalah suatu konstanta (tegas) sebagai konsekuen. Semua tahapan dalam penalaran fuzzy Tsukamoto sama dengan fuzzy Sugeno dan yang membedakannya adalah konsekuen yang digunakan pada Sugeno adalah konstanta (Minarni and Aldyanto, F. 2016).

Pada penelitian ini menggunakan 9 aturan fuzzy yang diterapkan untuk inferensi. Berikut merupakan aturan aturan yang digunakan dalam perhitungan prediksi pemesanan Roti Jordanmenggunakan metode Tsukamoto dan Sugeno.

If permintaan sedikit and persediaan sedikit then pemesanan sedikit

If permintaan sedikit and persediaan sedang then pemesanan sedikit

If permintaan sedikit and persediaan banyak then pemesanan sedikit

If permintaan sedang and persediaan sedikit then pemesanan sedang

If permintaan sedang and persediaan sedang then pemesanan sedang

If permintaan sedang and persediaan banyak then pemesanan sedang

If permintaan banyak and persediaan sedikit then pemesanan banyak

If permintaan banyak and persediaan sedang then pemesanan banyak

If permintaan banyak and persediaan banyak then pemesanan banyak

Tahap yang terakhir dari inferensi fuzzy Tsukamoto dan Sugeno adalah menghitung hasil akhir dari perhitungan yang sudah dilakukan berdasarkan aturan aturan yang digunakan, dalam menghitung hasil akhir metode fuzzy Tsukamoto dan Sugeno menggunakan rata-rata terbobot.

Memodelkan fungsi variabel

Permintaan (x)
Rumus dalam menghitung hasil akhir dari inferensi fuzzy Tsukamoto dan Sugeno adalah:

$$
\mathrm{Z}=\frac{\sum a 1 . \mathrm{Z} 1}{\sum a 1}
$$

Dimana $\mathrm{i}=$ banyaknya aturan yang digunakan.

Presentase Error

$\frac{\mid(\text { persediaan }+ \text { prediksi) }- \text { Permintaan } \mid}{\text { Permintaan }} \times 100 \%$

Berikut proses tahapan perhitungan prediksi pemesanan Roti Jordan lapis rasa coklat dengan menggunakan metode fuzzy Tsukamoto dan Sugeno. Dengan informasi dari data pembelajaran bulan Januari pada PD. Nur Berkah Jaya menunjukan data transaksi sebagai berikut: Dengan rule sebagai berikut:

If permintaan sedikit and persediaan sedikit then pemesanan sedikit

If permintaan sedikit and persediaan sedang then pemesanan sedikit

If permintaan sedikit and persediaan banyak then pemesanan sedikit

If permintaan sedang and persediaan sedikit then pemesanan sedang

If permintaan sedang and persediaan sedang then pemesanan sedang

If permintaan sedang and persediaan banyak then pemesanan sedang

If permintaan banyak and persediaan sedikit then pemesanan banyak

If permintaan banyak and persediaan sedang then pemesanan banyak

If permintaan banyak and persediaan banyak then pemesanan banyak

Permintaan paling sedikit $=630$ dan Permintaan terbanyak $=900$

Persediaan paling sedikit $=0$ dan persediaan terbanyak $=200$

Pemesanan pembelian paling sedikit $=600$ dan pemesanan pembelian terbanyak $=900$

Adapun tahapan-tahapan perhitungannya adalah sebagai berikut ini:

1. Fuzzyfikasi 


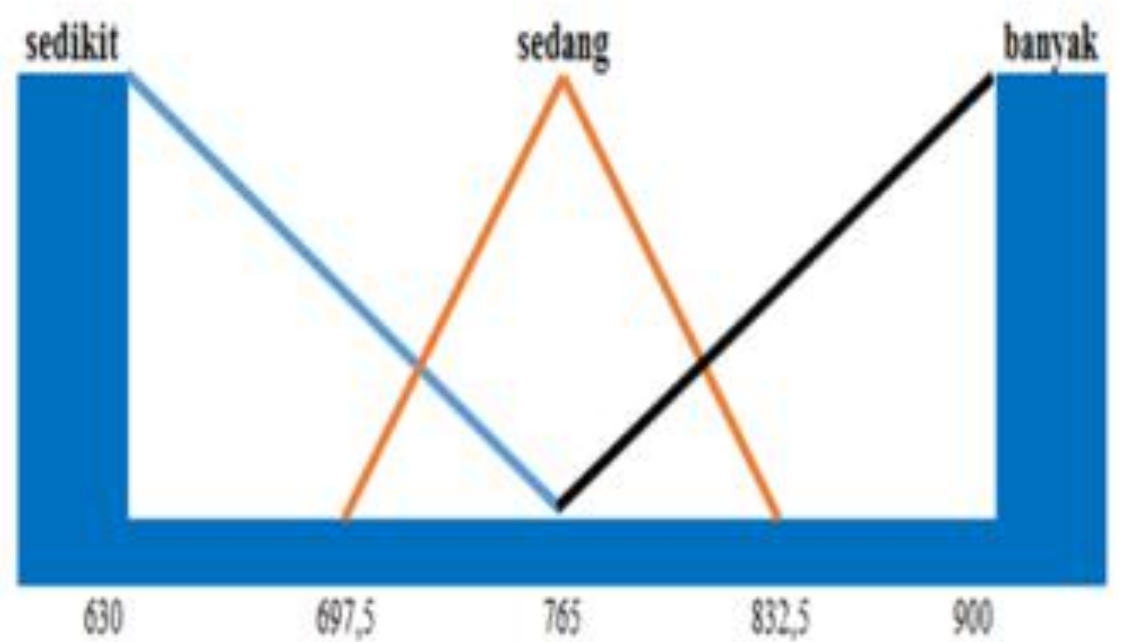

Gambar 1. Grafik area fungsional variabel permintaan(x)

$\mu$ Permintaan sedikit $[\mathrm{x}]\left\{\begin{array}{c}0, x \geq 765 \\ \frac{765-x}{765-630}, \quad 630<x<765 \\ 1, x \leq 630\end{array}\right.$

$\mu$ Permintaan sedang $[x]\left\{\begin{array}{c}0, x \geq 832,5 \text { dan } x \leq 697,5 \\ \frac{x-697,5}{765-697,5}, 697,5<x<765 \\ \frac{832,5-x}{832,5-765}, 765<x<832,5 \\ 1, x=765\end{array}\right.$

$\mu$ Permintaan banyak $[x]\left\{\begin{array}{c}0, x \leq 765 \\ \frac{x-765}{900-765}, \quad 765<x<900 \\ 1, x \geq 900\end{array}\right.$ 
Persediaan (y)

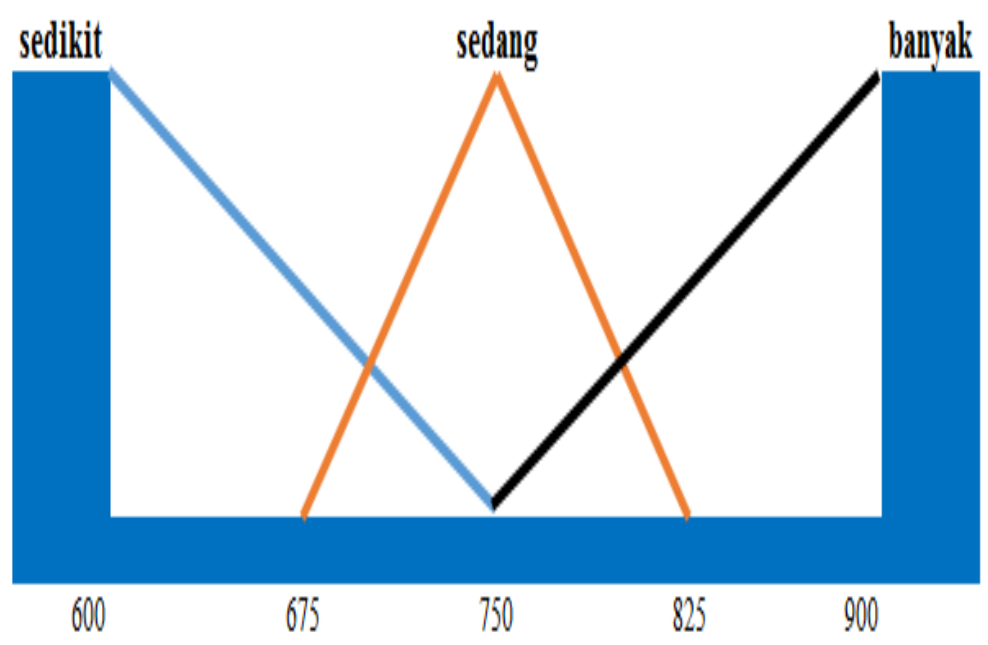

Gambar 2. Grafik area fungsional variabel Persediaan (y)

upersediaan sedikit $[y]\left(\begin{array}{c}0, y \geq 100 \\ \frac{100-y}{100-0}, 0<y<100 \\ 1, x \leq 0\end{array}\right.$

upersediaan sedang $[y]$ ] $\left\{\begin{array}{l}0, y \geq 150 \text { dan } y \leq 0 \\ \frac{y-50}{100-50}, 50<y<100 \\ 150-y\end{array}, 100<y<150\right.$

$$
\left\{\begin{array}{c}
\frac{150-y}{150-100}, 100<y<150 \\
1, y=100
\end{array}\right.
$$

upersediaan banyak $[y]\left\{\begin{array}{c}0, y \leq 100 \\ \frac{y-100}{200-100}, 100<y<200 \\ 1, y \geq 200\end{array}\right.$ 


\subsection{Perhitungan Hasil Akhir}

Hasil prediksi Tsukamoto

$\mathrm{Z}=\frac{\sum a 1 . \mathrm{Z} 1}{\sum a 1}$

$\mathrm{Z}=((0 * 750)+(0,852 * 622,2)+(0 * 750)+(0 * 675)+(0 * 675)$

$+$

$(0 * 675)+(0 * 750)+(0 * 075)+(0 * 750))$

$/(0+0,852+0+0+0+0+0+0+0)$

$\mathrm{Z}=(530,1144) /(0,852)$

\section{$\mathrm{Z}=622,2$}

Hasil prediksi Sugeno

$\mathrm{Z}=\frac{\sum a 1 . \mathrm{Z} 1}{\sum a 1}$

$\mathrm{Z}=((0 * 550)+(0,852 * 550)+(0 * 550)+(0 * 550)+(0 * 550)+($

$0 * 550)$

$+(0 * 550)+(0 * 550)+(0 * 550))$

$/(0+0,852+0+0+0+0+0+0+0)$

$\mathrm{Z}=(468,6) /(0,852)$

\section{$\mathrm{Z}=550$}

Jadi pada prediksi yang dilakukan Jadi pada prediksi yang dilakukan pada tanggal 4 Februari 2017 dengan data pembelajaran bulan Januari 2017, menghasilkan prediksi yang dilakukan dengan metode Tsukamoto= 622,2 dan dengan menggunakan metode Sugeno $=550$, sedangkan persentasi error dari masing-masing prediksi dapat dihitung dengan cara sebagai berikut:

$\frac{\mid \text { (persediaan }+ \text { prediksi) }- \text { Permintaan } \mid}{\text { Permintaan }} \times 100 \%$

Persentasi eror Tsukamoto:

$\frac{|(100+622,2)-650|}{650} \times 100 \%=0,107692 \%$

Persentase eror Sugeno:

$\frac{|(100+550)-650|}{650} \times 100 \%=0 \%$

Berdasarkan data hasil prediksi dari tabel Februari sampai dengan Desember 2017 maka dapat diketahui jumlah persen eror dari setiap bulan prediksi seperti yang ditampilkan pada tabel. 2 dibawah ini:

Tabel 2. Jumlah Persen Error Pada Tiap Bulan Prediksi

\begin{tabular}{llll}
\hline \multirow{2}{*}{ Bulan } & \multicolumn{2}{l}{ Total Error Prediksi } & $\begin{array}{l}\text { Banyaknya } \\
\text { Prediksi }\end{array}$ \\
\cline { 2 - 3 } & Tsukamoto & Sugeno & \\
\hline
\end{tabular}

\begin{tabular}{|c|c|c|c|c|}
\hline Febuari & 0,321764927 & 0 & 4 & \\
\hline Maret & 0,426696732 & 0 & 4 & \\
\hline April & 2,846920613 & 0,419048 & 4 & \\
\hline Mei & 2,125174352 & 0 & 4 & \\
\hline Juni & 12,94948235 & 0 & 4 & \\
\hline Juli & $\begin{array}{l}- \\
0,158233123\end{array}$ & 0 & 5 & \\
\hline Agustus & 3,744986165 & 0,408266 & 4 & \\
\hline September & 0,614467726 & 0 & 5 & \\
\hline Oktober & & 0,448658215 & 0 & 4 \\
\hline November & & 0,269407914 & 0 & 4 \\
\hline Desember & & 0,112230781 & 0 & 5 \\
\hline
\end{tabular}

Berdasarkan informasi yang didapat dari tabel. 2 maka dapat dihitung rata rata absolut eror prediksi pertahun 2017 dari metode Tsukamoto dan Sugeno sebagai berikut:

1. Rata rata absolut persen eror dari hasil prediksi metode tsukamoto:

$\frac{\text { Dpersen eror }}{\text { jumlah prediksi }}=\frac{23,70155666}{47}=0,504288 \times 100 \%=$ 0,504288

2. Rata rata absolut persen eror dari hasil prediksi metode sugeno:

$\frac{\text { Dpersen eror }}{\text { jumlah prediksi }}=\frac{0,827346}{47}=0,017602 \times 100 \%=0,0176 \%$

Berdasarkan hasil yang diperoleh dari hasil prediksi Pemesanan roti jordan menggunakan metode fuzzy inferensi tsukamoto dan sugeno mengacu pada data tahun 2017 yang dilakukan sebanyak 47 kali prediksi, menunjukan bahwa perhitungan prediksi tsukamoto memiliki rata - rata absolut erornya lebih besar yaitu $0,504288 \%$ dibandingkan pada perhitungan prediksi menggunakan metode sugeno dengan rata - rata absolut eror yaitu $0,0176 \%$

\section{Kesimpulan}

Perhitungan prediksi menggunakan metode sugeno menghasilkan rata rata absolut persen eror yang lebih kecil dibandingkan dengan menggunakan metode tsukamoto maka dapat diambil kesimpulan pula bahwa metode sugeno lebih baik digunakan dalam menghitung prediksi pemesanan roti jordan dibandingkan dengan metode tsukamoto karena metode sugeno memilki tingkat kebenaran prediksi rata rata $0,0176 \%$ sedangkan tingkat kebenaran prediksi rata rata metode tsukamoto adalah $0,504288 \%$.

\section{Daftar pustaka}

Minarni and Aldyanto, F. "Prediksi Jumlah Produksi Roti Menggunakan Metode Logika Fuzzy (Studi Kasus: Roti Malabar Bakery)." Jurnal TeknoIf 4.2 (2016).

Ayuningtias, Laras Purwati, and Jumadi Jumadi. "Analisa Perbandingan Logic Fuzzy Metode Tsukamoto, Sugeno, Dan Mamdani (Studi Kasus: 
Prediksi Jumlah Pendaftar Mahasiswa Baru Fakultas Sains Dan Teknologi Universitas Islam Negeri Sunan Gunung Djati Bandung)." Jurnal Teknik Informatika UIN Syarif Hidayatullah 10.1. (2017).

Meimaharani, Rizkysari, and Tri Listyorini. "Analisis Sistem Inference Fuzzy Sugeno dalam Menentukan Harga Penjualan Tanah untuk Pembangunan
Minimarket." Simetris: Jurnal Teknik Mesin, Elektro dan Ilmu Komputer 5.1 (2014): 89-96.

Azmi, Tatak Ulul, Hanny Haryanto, and T. Sutojo. "Prediksi Jumlah Produksi Jenang di PT Menara Jenang Kudus Menggunakan Metode Logika Fuzzy Tsukamoto." Sisfotenika8.1 (2018): 23-34. 